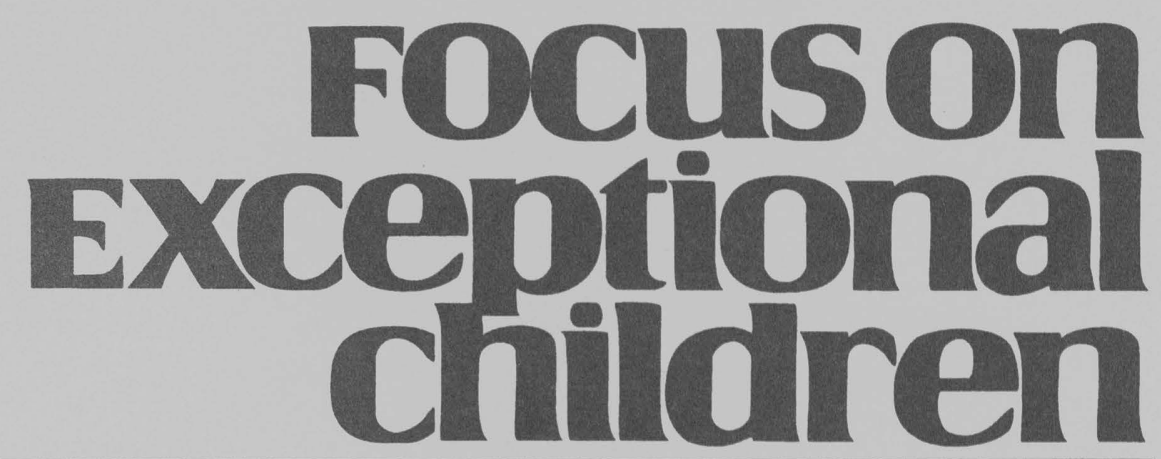

\title{
Critical Cultural Knowledge in Special Education: Reshaping the Responsiveness of School Leaders
}

\author{
Khaula Murtadha-Watts and Edy Stoughton
}

Issues related to the cultural diversity of students, faculty, and communities increasingly dominate the current debate in education. Race, class, gender, and disability have all been important foci for researchers interested in school restructuring (see the American Educational Research Association Annual Meeting Program, 1998). Much of the discussion has been framed by scholars promoting multicultural curricula and better teacher preparedness for working with children who differ in ethnicity and social class. Other scholars are attempting to enhance the competence of teachers for working with children who have special needs. Still others are drawing attention to the interconnectedness and effects of ableism, sexism, classism, and racism. Very little research, however, has been directly linked to the cultural preparedness of school administrators who are responsible for curricular, instructional, pupil service, financial, and community relations leadership. The need for culturally responsive leaders is even more dramatic when we look at the effect of issues of culture and difference on special education. Many teachers in special education often work with school administrators who are responsible for providing instructional leadership and influencing overall school climate but have little knowledge of the specific learning theories and teaching strategies used with children who have special needs or of the multicultural issues that affect placement and services.

We begin this article with a discussion of the political and ideological dimensions of culture, cultural difference, and labeling. We follow with the assertion that administrators' beliefs, as expressions of personal values, are connected to their instructional behaviors and their leadership roles in schools (Hart \& Bredeson, 1996). Therefore, we make the argument that an administrator's personal commitment to becoming a multicultural person, concerned with disembedding deep-seated cultural biases and selfreflection, will contribute to schoolwide preparedness and responsiveness to cultural diversity and inclusion.

Next, we suggest that an important leadership role that is missing from the principal preparation literature is critical cultural mirroring, that is, speaking and acting across difference, to reflect to the staff possible biases, prejudice, and stereotyping that may exist while supporting school cohesion and a unifying climate. This role should serve as a foundation for working with teachers to help them recognize those times when multicultural issues are distinct from special educational needs as well as those times when issues of

Khaula Murtadha-Watts is the executive associate dean in the School of Education at Indiana University-Purdue University Indianapolis and on the faculty of the Teacher Leadership Program. Edy Stoughton is on the faculty of the Teacher Education Program in the School of Education at Indiana University-Purdue University Indianapolis. This article was adapted from a chapter in New Ways of Looking at Learning Disabilities: Connections to Classroom Practice, edited by Lou Denti and Patricia Tefft-Cousin and published by Love Publishing Company. 
cultural diversity and learning problems are symbiotic. This dimension of multicultural education is sometimes minimized or neglected by administrators, who may think of their role as being a curriculum development leader who is concerned only with content related to ethnic, racial, or other cultural groups.

Finally, we suggest that leaders who are attentive to cultural diversity and special education prioritize forming school communities as projects of possibilities, where students' successes are collective responsibilities rather than solitary struggles by individual teachers. Both special and general educators face major challenges in working together and with parents to provide appropriate, individualized education to students with disabilities from culturally diverse backgrounds. Recognizing the importance of parental input and that parents must be considered an integral part of the school community, we employ social contact theory to provide an understanding of the problems that occur in formal and informal situations when parents and educators from diverse backgrounds interact.

Our aim in this article is to enhance professional practice by drawing attention to the inadequacy of traditional leadership models and the way they respond to cultural differences,

\section{FOcuson Exceptional children}

ISSN 0015-511X FOCUS ON EXCEPTIONAL CHILDREN (USPS 203-360) is published monthly except June, July, and August as a service to teachers, special educators, curriculum specialists, administrators, and those concerned with the special education of exceptional children. This publication is annotated and indexed by the ERIC Clearinghouse on Handicapped and Gifted Children for publication in the monthly Current Index to Journals in Education (CIJE) and the quarterly index, Exceptional Children Education Resources (ECER). The full text of Focus on Exceptional Children is also available in the electronic versions of the Education Index. It is also available in microfilm from Xerox University Microfilms, Ann Arbor, MI. Subscription rates: individual, \$36 per year; institutions, $\$ 48$ per year. Copyright (C) 2004, Love Publishing Company. All rights reserved. Reproduction in whole or part without written permission is prohibited. Printed in the United States of America. Periodical postage is paid at Denver, Colorado. POSTMASTER: Send address changes to:

$$
\begin{gathered}
\text { Love Publishing Company } \\
\text { Executive and Editorial Office } \\
\text { P.O. Box } 22353 \\
\text { Denver, Colorado } 80222 \\
\text { Telephone (303) } 221-7333
\end{gathered}
$$

\section{EDITORIAL BOARD}

Edwin Ellis University of Alabama
Tim Lewis

University of Missouri

Chriss-Walther Thomas

University of Kansas

Susan T. Warhover Editor
Stanley F. Love Publisher particularly for students who are in need of special education. In our view, leaders need to have a personal commitment to becoming multicultural people, to engage in critical cultural mirroring, and to develop parent collaborators in the school community. In these ways, critically reflective, morally caring educators can do a great deal to bring about change in culturally diverse school settings.

Central to this discussion is an understanding of our use of the term culture. We chose not to follow Geertz's (1973) well-known approach to thinking about culture as the "templates" or "webs of meaning" by which we organize "social and psychological experience." It appears to be devoid of the political and ideological dimensions important to our work. Bullivant (1993) defined culture as a group's program for survival in and adaptation to its environment. In this article, we use a critical cultural perspective, that draws attention to the asymmetrical power relations of the society that are maintained in schools and the deficit view of minority students that school personnel often uncritically and unknowingly hold (Bartolome, 1996). We believe that an education for students with special needs must take into account concerns for how groups struggle to make sense of their existence and thus requires an alternative leadership model embodying critical cultural knowledge for today's demographically changing schools.

\section{INTERSECTIONS OF CULTURAL DIFFERENCE AND LABELING}

Considered a reform movement, multicultural education is designed "to bring about a transformation of the school so students from both genders and from diverse cultural and ethnic groups will have an equal chance to experience success" (Banks, 1997). As noted by Banks and many others, some students, because of their backgrounds and particular characteristics, have a better chance to succeed in school as it is currently structured than do other students. The highly disproportionate number of male African Americans and Hispanics classified as learning disabled indicates the extent to which students from culturally diverse backgrounds experience discrimination or inadequate educational programs. Data from the U.S. Department of Education Office of Civil Rights (OCR, 1995) point to the many discriminatory practices in our schools that result in the overrepresentation of students from ethnic groups in special education. These data reveal differences in all of the following areas:

- Prereferral intervention (e.g., districts with predominantly White students have more extensive prereferral programs than do schools with predominantly African American students)

- Reasons for referrals for special education evaluations (e.g., for African American students, there is greater emphasis on behavioral reasons than on academic reasons for special education referral) 
- The factors used in the evaluations (e.g., greater reliance is placed on IQ tests in the evaluation of African American students)

- Placement in more restrictive settings (e.g., a disproportionate number of African American students are labeled as having mental retardation, the category in which students are most likely to be in separate settings) (OCR, 1995)

Students who have limited English proficiency face similar problems. The difficulties that teachers and clinicians have in distinguishing between language difference and language disability are documented in psychological and language assessment research. The use of a standardized language assessment approach has proved to be deficient and inadequate in assessing the dual language abilities of bilingual students.

As noted by Meadmore (1993, cited in Lipsky \& Gartner, 1997) "race, gender and class intersect in discrimination and social injustice" (p. 2). At the time of Meadmore's study, for example,

- approximately $40 \%$ of secondary students in the general population came from households with annual incomes of less than $\$ 25,000$; for secondary students with disabilities, the percentage was $68 \%$; and

- whereas $25 \%$ of secondary students in the general population were living in single-parent families, $37 \%$ of youth with disabilities had a single parent.

Along a similar vein, Podell and Soodak (1993), who studied the referral of children from families of low socioeconomic status (SES), concluded that low-SES students may be at greater risk for referral because of teacher, rather than student, factors. In other words, teachers' "decisions about poor children are susceptible to bias when teachers perceive themselves as ineffectual" (p. 251).

School leadership must play a major role in drawing attention to racist and classist language, social, and gender inequities. To implement successful inclusive education programs, the support of the superintendent of schools and school board members is critical. However, we agree with Lipsky and Gartner (1997) that the role of the principal is central, as the school site is the key locus of educational services.

\section{BECOMING A MULTICULTURAL LEADER THROUGH DISEMBEDDING CULTURAL BIASES}

How does a principal lead a school to become a caring, culturally supportive community? Why does he or she need to? What are the compelling reasons for such a leadership initiative? In an attempt to be color-blind and to treat all students equally, to be impartial and fair, many educators do not want to acknowledge cultural differences. In a sincere fashion, they often say "I don't see black or white, rich or poor. I see only students." However, as Gollnick and Chinn
(1998) informed us, teachers base their expectations about student achievement on such characteristics such as first language, race, socioeconomic status, and gender. Principals need to recognize the impossibility of cultural neutrality among fellow administrators, staff, and students, and their own efforts to be objective may in fact impede the goal of providing the best education for all students. Many teachers prefer to think that students' lack of interest and poor academic achievement are due solely to conditions in their homes or are innately a part of diverse students' cultures-the cultural deficit myth (Contreras \& Delgado-Contreras, 1991). If an educator sees the cultures of people of color and people from low socioeconomic class as a problem, his or her attention is likely to be deflected from understanding that the majority group in this society perpetuates discrimination and inequality. These patterns have several implications for educational leadership interested in improving the academic achievement of all children as well as their life chances.

For instance, the patterns suggest that school leadership is a moral activity. "Moral" is being used here in its professional, cultural, and ethical sense. As Foster (1986) pointed out, the moral side of administration has to do with those attempts administrators make to bring resolution to dilemmas as they present themselves in day-to-day life in schools. School leaders must raise questions about cultural dilemmas, including beliefs about linguistic, gender, ethnic, and ability differences. Further, they need to ask about poverty and equity. Because we are all part of a society that is racist and stratified by ability, class, and language, all of us (both children and adults) have consciously and subconsciously internalized some of these ideologies.

As Nieto (1996) cautioned, a reeducation processlearning new things and unlearning some of the old-can be difficult and sometimes painful. One important step is to have a greater level of self-knowledge. This means critically reflecting on culturally informed behaviors, beliefs, and values and naming the historical situatedness of cultural phenomena. For the moral leader, this naming act-this surfacing - serves to identify his or her location in the process of learning and knowing. It is our belief that an administrator's self-reflection may contribute to schoolwide responsiveness to cultural diversity.

Freire and Macedo (1996) noted that the process of learning and knowing requires dialogue in which the sharing of experiences needs to be infused with an ideological analysis and a political project capable of eradicating oppressive practices and institutions both in education and society. Principals may develop these perspectives when they become deeply dissatisfied with the trivialization of complex educational and societal problems and the simplistic remedial plans that result from this kind of thinking. For some, a sense of mission is a driving force in their fight against oppression and inequity, and for others, a desire for radical change, through special relationships with 
colleagues, friends, and mentors with whom they have an honest sharing of previously unexamined values.

\section{CRITICAL CULTURAL MIRRORING AND CULTURALLY FOCUSED DIALOGUE}

We have coined the term critical cultural mirroring to refer to the ability of a school leader to speak and act across difference to reflect to the staff possible biases, prejudice, and stereotyping. Critical cultural mirroring is, for example, needed to raise the awareness that differential treatment is given to students based on their presumed deficits and teacher bias. Discourse is also needed to uncover the sedimented layers of beliefs and biases that result in students from low-income families and children from marginalized groups being mislabeled and inappropriately targeted for special education programs.

Critical cultural mirroring is similar to Gitlin and Smyth's (1989) dialogical approach to understanding. As a part of staff professional development, teacher evaluation, and program assessment, educators-both teachers and administrators alike-must begin to question why things are the way they are. Through culturally focused dialogue, they can begin to see how social, historical forces affect their own students, advantaging some and disadvantaging others. If this dialogue does not exist in the school culture, there are several roles that principals must play. They must be initiators of change, supporters for multicultural curriculum development, and facilitators for collaboration.

Leaders are crucial for initiating organizational change "because they act as a constant source of pressure to think in ways that deviate from the current culture" (Louis \& Kruse, 1995, p. 39). They can stimulate a slow-to-change staff with the urgency and seriousness of dialogue about curriculum that examines the impact of cultural beliefs on content and instructional strategies that are planned and in place, both explicit and implicit. (In such dialogue, it is crucial to discuss what we do not teach in schools as well as what we do.) Because the process of making curriculum decisions is so important, we need to understand how educators make such decisions and to consider how the process can and should be questioned. This is the focus of the next section of this article.

\section{CHALLENGES FOR CURRICULUM DEVELOPMENT: CULTURALLY FOCUSED DIALOGUE ABOUT CURRICULUM}

A cycle of culturally focused dialogue helps bring to the surface embedded beliefs and instructional practices. An example of a culturally focused dialogue would be one where school leadership recognized a deficit model of teaching and learning and brought it to the attention of faculty as a schoolwide, ongoing concern. The point might be raised that educators who are invested in "fixing" defects within the child are not involved in examining how the climate and academic curriculum may have contributed to learning or behavior problems.

Questions that would support such a cycle of dialogue includes the following:

- How does the content of the curriculum (or specific lessons) serve certain established interests and points of view while marginalizing or excluding others? Whose culture is valued?

- How can the curriculum be constructed and connected to the lived experiences of children and families from different cultural backgrounds? What fit exists?

- How can instruction include inquiry by teachers and students that increases understanding?

- What social responsibility and social action will the education lead to?

Classrooms in which a majority of the students are uninvolved, off task, and not learning are commonplace across the country (Goodlad, 1984). Yet, rather than examining ways to change the climate and curriculum to engage the students, many teachers cling to the belief that the students themselves are the problem. A vicious cycle begins in which low-achieving students from poor and minority backgrounds receive instruction that emphasizes low-order skills and repetitious drills (Maeroff, 1998). If they don't respond to the watered-down instruction, they are likely to then be referred for testing for special education. Special education placement has, in this way, been the result of a continuum of misreading student behavior, beginning with an inadequate understanding of divergent learning styles and cultures, with the end result being a continuation of the same low-order thinking skills curriculum that did not work in the first place.

The responsibility of administrators in such situations is to engage in the process of cultural mirroring with the teacher. One way that cultural mirroring could be carried out is to examine communication styles, including the messages people send, often unintentionally, as they interact (Flinders, 1994). Many communication problems can occur between teachers and students from different cultures simply because they are behaving in ways that are accepted and normative in their own cultures but problematic in the culture of the other person. As an example, children who are being considered for special education services often indicate, when questioned, that they "shut themselves off" from responding to a particular teacher because they are convinced that she or he "doesn't like them" (Silverstein \& Krate, cited in Franklin, 1992). The entire affective climate in such situations can be altered by pinpointing the cultural messages that are being misunderstood by the students and teachers. In some cases, this will lead to a reconsideration of the need of special education services. 
In addition to sensitizing school personnel to communication discrepancies between cultures, administrators need to be aware of how mismatches between the curriculum and the learning styles of certain students can lead to failure. When students are labeled mentally retarded and yet function well in all areas of their lives except for school, it is important to examine what other factors could be contributing to the academic problems. Again, are we looking for deficits within these children when we should be examining how schools are failing to reach them? Are we asking if curriculum and instruction are relevant to them? Are we building on the strengths that they are able to demonstrate in other environments? Is assessment bias leading us to see students as deficient rather than culturally different and leading to further bias in placement decisions?

An important goal of administrators is to pose these types of critical questions to teachers and to work with them to reorganize instruction to engage students' specific interests and prior knowledge. The questioning brings to light the problems inherent in teaching that avoids cultural responsiveness; the goal should be to draw attention to ways in which teachers can develop culturally responsive teaching practices. A shift must occur from cultural deprivation to increased attentiveness to the uniqueness of children.

School leaders (including lead teachers) must work with teachers, observing and creating analytical self-reflective texts about their teaching and helping them to unpack their assumptions about the curriculum. School leaders must also help teachers to provide learning that truly engages students and at the same time is authentic, rigorous, and thought provoking. Good teachers facilitate a safe, risk free learning environment that values each student's contributions. The understanding that exemplary education takes place when each student's gifts and talents are valued, when young people and adults learn to respect each person's individual strengths and weaknesses, has provided the vision that undergirds the move to inclusionary classrooms.

In evaluating their teaching, most teachers use a number of criteria. Three criteria that we suggest follow. Ross, Bondy, and Kyle (1993) pointed out that many teachers tend to focus only on the first of these. They noted that the second and third are evaluative questions that make teaching a profession as opposed to a technical skill. The criteria are:

1. Does what I am doing work? Is it possible for me to implement a particular strategy or approach?

2. Are my teaching approaches educationally sound? Are the children learning appropriate attitudes, values, concepts, and skills using methods that are consistent with good pedagogy?

3. Are my teaching approaches ethically defensible? Are the children learning in ways that will enable them to grow up to be responsible members of their community and as citizens who can participate fully and intelligently in a democratic society? Am I treating each child with dignity and respect and with regard to his or her specific needs? Are the children developing capacities for caring and being cared for or concern about others in the world?

These criteria are also useful to teachers who wish to engage in dialogue with their colleagues about teaching practices with children with special needs from diverse cultural groups.

\section{PARENTS AND THE FORMATION OF SCHOOL COMMUNITIES}

After many years of research, the link between parental involvement and student achievement is undeniable. Nevertheless, many parents remain distant from their child's school and see the school as an uninviting place. We believe that certain ethical behaviors and characteristics supported by all school community members can contribute to and emerge from effective collaborative relationships with parents. As noted by Friend \& Cook (1996), "these include beliefs and values that support collaboration, mutual trust, mutual respect, and establishment of a sense of community."

The idea of community and its importance for moving beyond artificial structures of individualism has become popular in contemporary scholarship. We find it useful in this discussion about special education and cultural diversity because teachers have traditionally viewed their work in isolation and exclusion, rarely looking critically at teaching and learning except when being evaluated or through self-criticism. If we are to change what happens in schools, an alternative model should be embraced that supports collaboration, team building, and cooperative work. It should be a model through which teachers can not only examine their classrooms and those of other teachers but can also engage with parents, administrators, other staff members, and students in deciding how educational environments can be improved for a changing society.

According to social contact theory (Allport, cited in Bennett, 1995), at least four basic conditions are necessary if social contact between groups of diverse cultural backgrounds is to be strengthened. To lessen prejudice and lead to attitudes and behaviors that support learning, the following conditions must be met:

1. Contact must be sufficiently intimate to produce reciprocal knowledge and understanding between groups.

2. Members of various groups must share equal status.

3. The contact situation should lead people to do things together. It should require intergroup cooperation to achieve a common goal.

4. There must be institutional support and authority and/or a social climate that encourages intergroup contact. 
Social contact theory is useful for understanding the formal and informal situations in which parents and educators from diverse backgrounds communicate. The second condition for strengthening social contact between groups-that is, that members of the groups share equal status-raises issues of power and authority in schools. All parents, especially those of low income, are not accorded the same standing or an equal standing with educators, when decisions or plans are made in schools.

Two of the formal occasions in which parents of students with special needs and educators meet are when the initial placement assessment process has been completed and in the required annual case review meeting during which plans are made for the child's individualized educational program (IEP) for the following school year. Both of these conferences are mandated by law, and both are expected to be conducted in compliance with a set of federal guidelines as set out in the Individuals With Disabilities Education Act (IDEA). The purpose behind these conferences and their structure is to ensure that parents of children with disabilities will play an integral and important part in the educational plans instituted for their children. Unfortunately, in many instances, the very process intended to provide a more active role for parents has actually tended to cause parents to be less involved.

From their research, concerning parent involvement in special education, Meyer, Harry, and Sapon-Shevin (1997) found that whereas the law focuses on the creation of objectively verifiable documentation by parents and professionals, the volume and content of paperwork tends to be confusing, overwhelming, and intimidating for parents. It can be embarrassing for parents to indicate confusion or to ask for clarification and explanations. These same authors found that the structure of formal conferences, which focuses on written verification, casts parents in a passive role unless they possess the knowledge base and professional language that enable them to actively contribute to the process. There is, therefore, a cultural dissonance between all but the most sophisticated parents and educational personnel which creates a chasm of uncertainty and discomfort that is hard to surmount. This is in addition to the intimidation felt by minority parents as a consequence of the environment itself, in which they are frequently the only minority people in a room of "experts."

For special educators and other concerned school personnel to comprehend how the context of the formalized placement or case review conference frames the participation level of many parents, it is necessary to step back from a milieu that is comfortable and familiar to those of us who are professional educators and view this same milieu through the lenses of those who may be extremely uncomfortable in this environment. Although the intent of IDEA is for parents to be partners with the school system in planning for their children, parents are not given enough information to question effectively, and if they disagree with plans being made they are often placed in an adversarial position. Evans, Salisbury,
Palomboro, and Goldberg (1994) reported that professionals tend to have low expectations of parent participation, expecting parents to limit their contributions to agreeing with the professional recommendations and signing the forms.

Another barrier to the full and equal partnership between all parties involved with planning for a child's educational future is the manner in which disabilities are viewed. School personnel tend to view children through the medical model. This viewpoint sees the child in a clinical fashion, assuming that knowledgeable experts with sophisticated assessment tools can pinpoint with scientific accuracy remedial methods to correct the problem. The medical model identifies a disability through testing and then prescribes therapies in the form of IEPs. Because professionals possess information and terminology that are generally not possessed by parents, they become the experts controlling the discourse. Professional jargon lends authority to the educators' opinions while devaluing parent knowledge. Those parents without the social capital that permits participation in the conversation about their child are further alienated (Harry, 1997).

These asymmetrical power relations are rarely negotiated and maintain a barrier of silence that is buttressed by the formal, impersonal communication style that educators typically use during the meetings. Many parents become aware of the unequal balance of power and become resentful of this form of discussion. A basic mistrust develops that intensifies as parents consider the manner in which students are selected for special education programs, including the assessment tools and procedures that are used. Their feelings of mistrust can be exacerbated by awareness of the overrepresentation of African American children in special education programs and discomfort over the practice of locating learning problems solely within the child with no critical discussion about school contexts (Howe \& Miramontes, 1992).

Another problem is that, in most instances, assessment has already been completed and the educational personnel are in basic agreement about how they wish to proceed before the parents are brought into the picture. During the first meeting with parents, the proposed plan is explained to the parents; they are given the opportunity to ask questions; and then they are expected to sign the paperwork to indicate agreement with the plan. If parents disagree with the committee's recommendations, they can find themselves in a confrontive posture, faced with the consternation and disapproval of educational experts who sincerely believe that they know what is best for the child. Additionally, if parents disagree with some of the proffered strategies or feel the need to add or correct information to provide a better understanding of the child, they are often viewed as being adversarial and therefore as alienating the educators who are needed as allies. This is a far cry from a partnership of all concerned parties who are sharing their input on an equal basis and collaborating on an appropriate educational plan. Educators need to ask themselves whether the participation they desire 
is merely consent to a legal document, or is a true dialogue that has the purpose of discerning the nature of a child's learning or emotional need and how best to proceed with educational program planning.

The intention on the part of many school personnel in case conference meetings is not to ignore or intimidate parents. The conference is, however, often viewed by school personnel as a timeconsuming, cumbersome legality that should be completed as quickly and efficiently as possible. Because of the volume of paperwork school personnel must set aside extensive periods of time from already full teaching schedules just to complete the pages of written documentation in a perfunctory way. All too often, educators view this process as taking them away from their real work rather than as being an integral part of their work. Many also think parents are equally inconvenienced by the length of time the meeting takes, and they justify the tendency to expedite matters as sensitivity to parent work schedules and child care needs. However, this impatience with the volume of work and time required can translate to parents as a lack of desire to include them in the process. The cultural gap widens when parents perceive judgments about their skills in raising their children.

In light of all of these factors, the temptation for parents is strong to simply agree with what the experts are recommending and get through the process as quickly as possible. Teachers, too, may be uncomfortable and worry about possibly being "put on the spot" or having their expertise called into question by dissatisfied parents. Nevertheless, in looking at placement and annual educational plan reviews, where so much is at stake regarding a child's education, it is crucial that everyone has an opportunity to have input into plans for the child.

One way to improve the level of discourse would be for principals to monitor the affective atmosphere of the conference. By facilitating the discourse, principals can help to make the experience more beneficial to everyone involved. Parents should be welcomed on a respected basis as partners in the process, and there should be an understanding that their comments are no less credible because they are subjective and personal than are the technical assessments of the professional educators. Indeed, parents' comments provide invaluable insight into the cultural and social environment of the child. Because it is necessary to view children holistically, anecdotal and environmental information is crucial. Information about where the child is successful, about his or her experiences outside of the school, and about the quality of interactions in the settings of family and community is extremely important for seeing the child's strengths and weaknesses and for preventing a deficit view of the child.

Communication with parents could further be enhanced by bringing them into the process at an earlier point, that is, before assessment is complete and decisions have been made. If parents are an integral part of the assessment and planning team from the beginning, they will know that their role is not simply to agree or disagree with an already formulated plan but to provide input throughout the process. This involvement would also help prevent the commonly held perception that referral of a child for testing is tantamount to a decision that she or he is a special education student. With parents and educators working more closely together in an atmosphere of mutual sharing and respect, there would be a greater understanding of the roles of all participants and a leveling of the hierarchy. There would likely also be greater openness to points of disagreement and differences of opinion. The learning community would be viewed as a place for possibility, a place where an ethic of care is important, where trust is not taken for granted but worked for, and where openness to critique is available.

As schools struggle to become culturally responsive inclusive communities, their members must address such questions as the following:

Do we value diverse cultures entering the school community? If so, do we demonstrate this?

What kinds of reflective work will be necessary so that educators, parents, and children will see themselves as necessarily connected in a school community?

The responsibilities of educational administrators for developing schoolwide critical cultural knowledge go beyond merely citing legal requirements and developing job descriptions. Administrators must engage discourses of change that transcend the cacophony of special interests and the disinterest of those unwilling to be a part of a collaborative community. They must struggle for an environment where the voices of marginalized children and their families are not only heard but valued. Their most critical task is to enable others to act. (See appendix to this article.)

The principal's role as the leader-manager of a school is pivotal according to the effective schools literature. Yet, each building principal faces a unique set of challenges. While principals attempt to address various students' learning needs, they must also respond to parents' concerns, teachers' attitudes and professionalism, and a myriad of administrative duties. When administrators take seriously the moral imperative of responsiveness to the cultural differences of teachers, students, and families, they work to support inclusion while raising a critical cultural mirror to the staff and themselves. They schedule time for teachers to plan and to learn new knowledges and skills, fostering epistemological curiosity. Professional development about multicultural education is ongoing, just as our society is changing socially, politically, and economically. Intentional in their focus to build a school that is culturally responsive, that involves parents from diverse backgrounds, and that insures the appropriate education for children with special needs, school leaders understand that tensions and conflicts may arise but that even those tensions will lead to the growth of the learning community. 


\section{FOCUSO Exceptional children}

\section{APPENDIX}

Friend (1998) offered the following list of administrative responsibilities in inclusive schools. In our view, the list is highly useful as a starting point but does not reach far enough for critically thinking leaders.

1. Understand the legislative and legal requirements of least restrictive environment for students with IEPs.

2. Develop knowledge of and commitment to inclusive education as a philosophy that addresses all students with special needs, including those with disabilities. Make clear, public, and repeated statements setting inclusive practices as a standard for the school.

3. Understand and address accountability issues related to the provision of services for students with IEPs in inclusive settings.

4. Know common teacher concerns and questions about inclusive education and strategies for responding to them.

5. Know common parent concerns and questions about inclusive education and strategies for responding to them.

6. Provide needed staff development for all personnel affected by inclusive practices (e.g., teachers, paraprofessionals, tutors).

7. Involve staff in decision making concerning scheduling, student assignment, and other critical aspects of inclusive education.

8. Encourage staff to use innovative and experimental strategies for providing services to students. Strategies should relate to specific instructional approaches, service delivery models, the use of school personnel, and the allocation of time.

9. Create job descriptions that set expectations for staff to adopt and implement inclusive practices.

10. Establish hiring and personnel evaluation practices that foster the development of inclusive schools.

11. Work with staff to obtain "seed money" and other funds to foster the development of inclusive practices.

12. Address the needs of students with IEPs in the development of school policies, including testing and assessment, curriculum development, discipline policies, and report card grading.

13. Facilitate the creation and implementation of a plan for evaluating school initiatives related to inclusive education.

14. Create and use vehicles for involving all constituent groups in the development of school practices related to inclusion (e.g., parent groups, unions, and local advocacy groups for individuals with disabilities).

\section{REFERENCES}

American Educational Research Association. (1998). Annual meeting program. San Diego, CA.

Banks, J. (1997). Multicultural education: Characteristics and goals. In J. A. Banks \& C.A.M. Banks (Eds.), Multicultural education: Issues and perspectives (3rd ed., 3-31). Boston: Allyn \& Bacon.
Bartolome, L. (1996). Beyond the methods fetish: Toward a humanizing pedagogy. In P. Leistyna, A. Woodrum, \& S. Sherblom (Eds.), Breaking free: The transformative power of critical pedagogy (229252). Cambridge, MA: President and Fellows of Harvard College.

Bennett, C. (1995). Comprehensive multicultural education: Theory and practice. (3rd ed.). Boston: Allyn \& Bacon.

Bullivant, B. (1993). Culture: Its nature and meaning for educators. In J. A. Banks \& C.A.M. Banks (Eds.), Multicultural education: Issues and perspectives (2nd ed.), 29-47. Boston: Allyn \& Bacon.

Cinnamond, J. (1995). Safeguarding empowerment. In B. Kanpol \& P. McLaren (Eds.), Critical multiculturalism. Westport, CT: Bergin \& Garvey.

Evans, I. M., Salisbury, C., Palomboro, M., and Goldberg, J. S. (1994). Children's perception of fairness in classroom and interpersonal situations involving peers with disabilities. Journal of the Association for Persons with Severe Handicaps, 19, 326-332.

Ford, A., Davern, L, \& Schorr, R. (1992). Inclusive education: "Mak ing sense" of the curriculum. In S. Stainbeck \& W. Stainbeck (Eds.), Curriculum considerations in inclusive classrooms (37-61). Baltimore: Paul H. Brookes

Foster, W. (1986). Paradigms and promises: New approaches to educational administration. Buffalo, NY: Prometheus Books.

Franklin, M. (1992). Exceptional Children, 59(2), 115-122.

Freire, P., \& Macedo, D. (1996). A dialogue with Paulo Freire. In P. McLaren \& P. Leonard (Eds.), Paulo Freire: A critical encounter. London: Routledge..

Friend, M. (1998). Collaboration the key to urban educational success. Paper presented at the first Indiana Urban Superintendent's Association/ IUPUI Conference, July. Indianapolis, IN.

Friend, M., \& Cook, L. (1996). Interactions: Collaboration skills for school professionals. New York: Longman.

Geertz, C. (1973). The interpretation of cultures. New York: Basic Books.

Gitlin, A., \& Smyth, J. (1989). Teacher evaluation: Educative alternatives. New York: Falmer Press.

Gollnick, D. M., \& Chinn, P. (1998). Multicultural education in a pluralistic society (5th ed.). Upper Saddle River, NJ: Merrill.

Goodlad, J. (1984). A place called school. New York: McGraw-Hill.

Graden, J., \& Bauer, A. (1992). Using a collaborative approach to support students and teachers in inclusive classrooms. In S. Stainbeck \& W. Stainbeck (Eds.), Curriculum considerations in inclusive classrooms (85-100). Baltimore: Paul Brookes Publishing.

Harry, B. (1997). Cultural diversity, families; and the special education system: Communication and empowerment. New York: Teachers College Press.

Hart, A., \& Bredeson, P. (1996). The principalship: A theory of professional learning and practice. New York: McGraw-Hill.

Howe, K., \& Miramotes, O. (1992). The ethics of special education. New York: Teacher's College Press.

Lipsky, D., \& Gartner, A. (1997). Inclusion and school reform: Transforming America's classrooms. Baltimore: Paul H. Brookes.

Louis, K., \& Kruse, S. (1995). Professionalism and community. Thousand Oaks, CA: Corwin Press.

Maeroff, G. (1998). Altered destinies. New York: St. Martin's Press.

Marion, R. (1979). Minority parent involvement in the IEP process. A systematic model approach. Focus on Exceptional Children, 10(8), $1-16$.

Meyer, L., Harry, B., \& Sapon-Shevin, M. (1997). School inclusion and multicultural issues in special education. In J. A. Banks \& C.A.M. Banks (Eds.), Multicultural education: Issues and perspectives (3rd ed., 334-354).New York: Wiley.

Podell, D. M., \& Soodak, L. C. (1993). Teacher efficacy and bias in special education referrals. The Journal of Educational Research, 86(4), 247-253.

Ross, D., Bondy, E., \& Kyle, D. (1993). Reflective teaching for student empowerment. New York: Macmillan. 